\title{
O Observatório Regional como ferramenta de gestão nos Institutos Federais de Educação, Ciência e Tecnologia: o caso do Instituto Federal do Paraná
}

Gilmar Jose Hellmann

Instituto Federal do Paraná (Ifpr)

Recebido: 04/04/2014 Versão revisada (entregue): 21/03/2015 Aprovado: 06/05/2015

\begin{abstract}
Resumo
Tendo como estudo de caso o Observatório Regional do IFPR, propõe-se definir o que seja o Observatório no contexto das organizações que o viabilizam e indicar a importância de indicadores e índices que subsidiam as informações aí utilizadas. A partir do interesse do governo federal em qualificar pessoas para o mercado de trabalho formou-se a Rede Federal de Educação Profissional, Científica e Tecnológica, constituída de instituições educacionais atuantes no ensino técnico básico e superior, conhecidas como Institutos Federais de Educação Tecnológicas ou IFET. As unidades dessas instituições de ensino visam atender às demandas de desenvolvimento regional e local em todo o território nacional. Fundamenta-se nos documentos governamentais e institucionais a corroboração do planejamento institucional com os princípios da sustentabilidade. Partindo-se de estudo de caso, propõe-se uma metodologia para iniciar e desenvolver as atividades do Observatório, aproximando os propósitos institucionais das necessidades locais, sinalizando a possibilidade de replicação do Observatório em outras instituições públicas e privadas no país.
\end{abstract}

Palavras-chave | Desenvolvimento regional; IFET; Instituto Federal de Educação, Observatório Regional; Rede Federal de Educação Profissional, Científica e Tecnológica.

Código JEL | H52; I28; R10.

THE REGIONAL OBSERVATORY AS MANAGEMENT TOOL IN THE FEDERAL INSTITUTES OF EDUCATION, SCIENCE AND TECHNOLOGY: THE CASE OF THE FEDERAL INSTITUTE OF PARANÁ

\begin{abstract}
Taking as case study the Regional Observatory in IFPR, its proposal defines the meaning of the center in the context of organizations which enables it; also it states the importance of indicators and indexes that support the information used in that. From the interest of the federal government to qualify people for the labor market resulted the Federal Network of Professional, Scientific and Technological Education, consisting of educational institutions
\end{abstract}


active in basic technical and higher education known as Federal Institutes of Technological Education or IFETs. These educational institutions units aim to meet the demands of regional and local development throughout the national territory. It is based on the governmental and institutional documents to corroborate the institutional planning with the principles of sustainability. Starting from this case study, the methodology proposes to initiate and to develop the activities of the Observatory, approaching the institutional purposes of local needs, signaling the possibility of replication of Observatory in other public and private institutions in the country.

Keywords | Federal Institute of Education; Federal Network of Professional Scientific and Technological Education; IFET; regional development; Regional Observatory.

JEL-Code | H52; I28; R10.

\section{EL OBSERVATORIO REGIONAL COMO HERRAMIENTA DE GESTIÓN EN LOS INSTITUTOS FEDERALES DE EDUCACIÓN, CIENCIA Y TECNOLOGÍA: EL CASO DEL INSTITUTO FEDERAL DE PARANÁ}

\section{Resumen}

Tomando como caso de estudio el Observatorio Regional del IFPR, se propone definir lo que es el Observatorio en el contexto de las organizaciones que lo hacen viable y especificar la importancia de los indicadores e índices que soportan las informaciones que allí se utilizan. Apoyado en el interés del gobierno federal en cualificar personas para el mercado de trabajo se formó la Red Federal de Educación Profesional, Ciencia y Tecnología, constituida por las instituciones dedicadas a la educación técnica básica y superior, los Institutos Federales de Educación Tecnológica o IFET . Las unidades de estas instituciones educativas tienen como propósito satisfacer las demandas de desarrollo regional y local en todo el territorio nacional. Se basa en los documentos de gobierno la corroboración de la planificación institucional con los principios de la sostenibilidad. A partir de un estudio de caso se propone una metodología para iniciar y desarrollar las actividades del Observatorio, acercándose los fines institucionales a las necesidades locales, lo que puede indicar la posibilidad de la réplica del Observatorio en otras instituciones públicas y privadas en el país.

Palabras-clave | Desarrollo regional; IFET; Instituto Federal de Educación; Observatorio Regional; Red Federal de Educación Profesional, Ciencia y Tecnología.

Código JEL | H52; I28; R10.

\section{Introdução}

Para Siqueira (2003), o Observatório é lugar e espaço no qual "uma instituição controla ou exerce trabalho sobre tal e possui uma estrutura para proporcionar uma visão ampla”. Esse perfil de instituição estrutura-se a partir da década de 1980 e 1990, com a emergência das ciências sociais pós-modernas (CABRAL, 2004). Essas novas instituições são consequência das mudanças econômicas e sociais do mundo, da ascendência de novas economias mundiais, como os Trigres Asiáticos (OCAMPO, 2002), dos desafios humanitários (fome, miséria) e ecológicos 
(aquecimento global, poluição, catástrofes naturais), enfim, são organizações preocupadas com o desenvolvimento regional sustentável (HELLMANN, 2013).

Nesse contexto, o Observatório pode ser relevante ferramenta de gestão para se obter informações sociais e econômicas de interesse da instituição. A organização deste espaço pode ser iniciativa de diversos setores sociais: de organismos do setor privado, de Sociedade Civil de Interesse Público (OSCIP), como Observatório de Favelas ${ }^{1}$, e de Organização Não Governamental (ONG), como a World Wide Fund for Nature do Brasil (WWF)' ${ }^{2}$, de governos como o Observatório del Mercado de Trabajo del Mercosur ${ }^{3}$; ou de organizações internacionais, como o Global Social Observatory ${ }^{4}$. Também pode ser motivada por organismos que pretendem estabelecer metas futuras e monitorar ações presentes, possibilitando a socialização de dados e informações para diferentes públicos em nível mundial, regional e local (UM-HABITAT, 2013).

As dimensões do Observatório podem variar em razão de recursos humanos, físicos e financeiros de seus mantenedores e/ou formato organizacional (jurídicolegal). Em geral, o Observatório está associado ou faz parte de um organismo maior; sobretudo por causa dos subsídios para sua manutenção. O Observatório tende a transcender os vínculos internos da instituição, estabelecendo uma rede de relações externas a aquelas de acordo com sua dinamicidade, com o foco de trabalho e da equipe gestora. Estas relações servem para compartilhar experiências, práticas e metodologias de trabalho; podem ser na modalidade de intercâmbio de conhecimentos ou de prestação de serviços de consultoria ${ }^{6}$. Os

${ }^{1}$ Criado em 2001, no Rio de Janeiro, o Observatório de Favelas se concentra em questões sociais urbanas. Disponível em: < http://observatoriodefavelas.org.br>.

${ }^{2}$ A ONG WWF foi fundada em 1961 na Suíça, possuindo vários escritórios em todos os continentes. $\mathrm{O}$ foco principal são questões ambientais. Disponível em: $<$ http://www.wwf.org.br>.

3 Observatorio del Mercado de Trabajo del Mercosur. Disponível em: $<$ http://www.observatorio.net>.

${ }^{4}$ Global Social Observatorio (GSO). Disponível em: < http://gsogeneva.ch>.

${ }^{5}$ Cita-se, por exemplo, o Global Urban Observatory (GUO) da United Nations (ONU) que desenvolve e organiza indicadores urbanos orientados para as políticas, estatísticas e outras informações urbanas mundiais auxiliando os governos, as autoridades e as organizações da sociedade civil. In: UN-HABITAT (United Nations Human Settlements Programme). Global Urban Observatory. United Nations (ONU). 2003. Ou o Social Observatory do World Bank que socializa práticas econômicas de diminuição da pobreza em várias partes do mundo. In: WORLD BANK. Learning by Doing: The Social Observatory. March 20, 2013.

${ }^{6}$ Em 2008 a Federação das Indústrias do Paraná solicitou consultoria do Observatório de Prospectiva Tecnológica Industrial (OPTI), da Espanha, para prospectar os "Setores Portadores de Futuro para o Estado do Paraná”, visando sinalizar caminhos de construção do futuro para cada um dos setores e áreas mais promissores para a indústria do Paraná nos horizontes de 2015, 2018 e 2020, tendo em vista a aplicação de metodologia utilizada nos setores econômicos 
Observatórios desempenham atividades variadas como estudos, pesquisas, projetos, relatórios socioeconômicos, formação de banco de dados informacionais, estudo de caso de boas práticas e organização de cursos, fóruns, seminários e congressos, entre outros.

O Observatório Regional do Instituto Federal do Paraná (IFPR) surge a partir de autarquias federais. Tal projeto emana do planejamento integrado da Secretaria de Educação Profissional e Tecnológica (SETEC) e do Conselho Nacional das Instituições da Rede Federal de Educação Profissional, Científica e Tecnológica (CONIF), almejando implantar o Observatório Nacional do Mundo do Trabalho ${ }^{7}$.

A lista a seguir apresenta as principais características dos Observatórios pertencentes ou parceiros dos IFETs pesquisados ${ }^{8}$ nos sites dessas instituições.

1. A) Nome: Observatório Socioeconômico e Educacional.

B) Vinculo Institucional: Instituto Federal de Alagoas; Pró Reitoria de Desenvolvimento Institucional.

C) Equipe: Economista.

D) Propostas: Informações Institucionais, Socioeconômicas e Educacionais; Estudos e Pesquisas; Centralização dos dados relativos à região, correlacionando-os com outros parâmetros externos; Identificação de potencialidades locais, com vistas à prospecção de tendências; Disponibilização das informações fornecidas à sociedade, como forma de auxílio para a elaboração de trabalhos, assim como orientação de ações de políticas públicas e investimentos voltados ao desenvolvimento regional; Acompanhamento da evolução das informações relativas à estrutura física, administrativa e discente do Instituto Federal de Alagoas.

emergentes da Espanha. O estudo resultou nos documentos denominados Rotas Estratégicas ou Roadmapping Industriais do Paraná. Disponível em: FIEP. Rotas Estratégicas para o Futuro da Indústria Paranaense. Sistema Federação das Indústrias do Estado do Paraná/FIEP. Observatórios SESI/SENAI/IEL; Observatório de Prospectiva Tecnológica Industrial (OPTI) OPTI en América Latina. Espanha. 2009

7 O GT Observatório Nacional do Mundo do Trabalho, da Câmara de Extensão e FORPOREXT, integrante do Planejamento Integrado entre SETEC e CONIF, propôs criar um Observatório Nacional da Rede Federal da EPCT, constituído pelos observatórios locais das Instituições Federais de Ensino. Deve-se considerar que na ocasião já existiam algumas iniciativas localizadas dos Institutos de Minas Gerais e do Rio de Janeiro. In: Ministério da Educação. Planejamento Integrado SETEC/MEC - CONIF: Relatório das Oficinas realizadas em 2010; Ações do Planejamento Integrado. Secretaria de Educação Profissional e Tecnológica. CONIF. Dezembro de 2010. P. 64-67.

${ }^{8}$ A pesquisa (realizada pelo autor em fevereiro de 2014) pode ter limitações pelo fato de haver trabalhos referentes ou similares ao Observatório e não estarem disponíveis nos sites dos Institutos Federais. 
2. A) Nome: Observatório do Mundo do Trabalho.

B) Vinculo Institucional: Instituto Federal de Goiás; Pró-Reitoria de Extensão; Vínculos Núcleo de Observação/Sudeste - Instituto Federal Fluminense e Núcleo de Observação Centro-Oeste Instituto Federal de Goiás.

C) Equipe: Pesquisador Gestor, Pesquisador Orientador, Assistente em Administração, Economista e Estagiário.

D) Propostas: Revista (ISSN), Projetos de Estudos e Pesquisas, Estudo de Desenvolvimento Regional, Boletins Técnicos Dados e Indicadores Educacionais, Artigos e Pesquisas de Colaboradores, Apontamentos e Análises de Livros e Artigos, Sugestões de Leitura, Estudos de Implantação, Estudos Microrregionais, Subsídios à Oferta de Cursos, Pesquisa Sobre Estágio, Processos Seletivos, Estudos Setoriais.

3. A) Nome: Observatório Nacional do Trabalho e da Educação Profissional e Tecnológica.

B) Vinculo Institucional: Instituto Federal Sul-Rio Grandense. Reitoria.

C) Equipe: Pesquisador Gestor, Pesquisador Orientador, Bolsista (3).

D) Propostas: Políticas e diretrizes de desenvolvimento, Vocações e potencialidades regionais e locais, Mundo do Trabalho e Emprego, Demandas por profissionais e cursos, Empreendedorismo e Cooperativismo, Oferta de Educação, Caracterização e transformações da EPT, Egresso.

4. A) Nome: Observatório Nacional do Mundo do Trabalho.

B) Vinculo Institucional: Instituto Federal de Brasília (IFB); Grupo de Pesquisa CAPS - Campus Brasília.

C) Equipe: Professores (2) e Alunos pesquisadores.

D) Propostas: LINHA ECONOMIA: 1. "Política de ação afirmativa e sua eficácia no DF". 2. "Análise comparativa dos rendimentos de docentes de ensino superior público e privado no DF". LINHA GESTÃO E FINANÇAS: 3. "Competências profissionais dos cargos de gestão patrimonial e de materiais no setor público federal". LINHA EDUCAÇÃO PROFISSIONALIZANTE: 4. "Vocações, demandas e carências de educação profissionalizante em Sobradinho - DF". 5. "Metodologia de ensino-aprendizagem baseada na manipulação orientada de figuras dinâmicas em ambientes virtuais", As pesquisas e projetos de extensão em andamento contam com a participação ativa de alunos dos cursos Técnica em Serviços Públicos e Tecnólogo em Gestão Pública do IFB.

5. A) Nome: Diagnóstico do Município de Tubarão e Região. 
B) Vinculo Institucional: Instituto Federal de Santa Catarina, PRODIN - PróReitoria de Desenvolvimento Institucional, Diretoria de Gestão do Conhecimento.

C) Equipe: Diretora DGC, Técnicos (Assistente, Economista, Estatístico).

D) Propostas: Diagnóstico por microrregião na implantação de novos Campi.

6. A) Nome: Observatório Socioeconômico da Região Norte Fluminense.

B) Vinculo Institucional: Instituto Federal Fluminense, NEE, UENF CCH Centro de Ciências do Homem, UFF, UFRRJ, UNIVERSO = Consórcio Universitário de Pesquisa da Região Norte Fluminense.

C) Equipe: Consórcio Universitário de Pesquisa da Região Norte Fluminense

D) Propostas: O Projeto de Pesquisa intitulado Configuração do Mercado de Trabalho da Região Norte Fluminense: Mapeamento das Cadeias Produtivas e Alternativas de Geração de Empregos apoiado pela FAPERJ, Observatório Socioeconômico da Região Norte Fluminense, Boletim Informativo.

7. A) Nome: Observatório do Mundo do Trabalho.

B) Vinculo Institucional: Instituto Federal de Rondônia.

C) Equipe: Pró-Reitoria de Extensão.

D) Propostas: Projeto de Extensão - Sem Publicação

8. A) Nome: Observatório Nacional do Mundo do Trabalho e da EPT.

B) Vinculo Institucional: REDENET - Consórcio CEFET e IFET Norte e Nordeste. Atualmente denomina-se Rede Nacional de Pesquisa e Inovação em Tecnologias Digitais - RENAPI.

C) Equipe: Consórcio Autônomo.

D) Propostas: Caracterização social, econômica e política da região de estudo; Políticas e estratégias de desenvolvimento sustentável; Vocações e potencialidades existentes, emergentes e potenciais; Arranjos produtivos, sociais e culturais; Estudos e pesquisas do mundo do trabalho e emprego; Programas, projetos e ações governamentais; Produção acadêmica relacionada à educação e trabalho; Caracterização e as transformações da EPT no mundo; Tecnologias emergentes e tendências mundiais; Experiências exitosas de EPT e sua interação com o mundo do trabalho. Estruturação de redes de parceiros e colaboradores na análise, produção e sistematização de informação do mundo do trabalho e a EPT e na proposição de ações de aperfeiçoamento desses campos. Articulação contínua da EPT com o mundo do trabalho, os setores produtivos e as políticas governamentais de desenvolvimento. Sistematização de informações do mundo do trabalho e da EPT que reflitam as demandas e necessidades das respectivas regiões 
A pesquisa encontrou algo referente aos Observatórios em aproximadamente 20\% dos IFETs do país, sendo atualmente 38 unidades, excluso a deste estudo. Conforme a lista anterior, os Observatórios possuem diversidade em relação: aos nomes (mundo do trabalho, socioeconômico, educacional, etc.); ao pertencimento interno e externo (Reitoria, Pró-Reitoria, Pesquisa, Extensão, etc.); e as propostas de atividades e produtos. Subentende-se a carência de diretrizes comuns para a constituição destes organismos ${ }^{9}$. Se não houve uniformidade nesse sentido, a definição abaixo aponta características comuns aos Observatórios, como:

[...] um dispositivo de observação criado por organismos para acompanhar a evolução de um fenômeno, de um domínio ou de um tema estratégico, no tempo e no espaço. $\mathrm{Na}$ origem de um observatório deve existir uma problemática que possa ser traduzida sob a forma de objetivos, que permitam definir indicadores, cujo cálculo necessita a integração de dados e permita a realização de sínteses (FIEP/PR).

A existência do organismo também se deve a averiguação de problemática real, indicadores, dados e informações. Por isso, o tópico seguinte tratará da importância e de aspectos relativos à utilização de indicadores.

\section{Importância dos indicadores}

Os indicadores são dados tratados no intuito de parametrizar aspectos comuns em diferentes ambientes culturais. Normalmente quantificam aspectos socioeconômicos que se traduzem em informações qualitativas de acordo com os interesses comuns. Encontram-se sistemas de indicadores de diversos tipos, formatos e finalidades: "Algumas práticas utilizam-se de diversos indicadores de acordo com suas necessidades e necessitam selecionar diferentes métodos" (SHEN, 2011, p. 17). Em relação à finalidade, os indicadores são utilizados na melhoria de tomadas de decisão, especialmente em nível gerencial. Os dados obtidos destes indicadores são utilizados nos setores públicos e privados, suprindo informações úteis para análise de ambientes interno e externo; no primeiro caso para identificar pontos fortes e fracos da organização, e no segundo para perceber limitações e oportunidades do macroambiente, somando-se ao método SWOTStrengths, Weaknesse, Opportunities, Threats. Os indicadores também são essenciais

\footnotetext{
${ }^{9}$ Em 2010 a Câmara de Extensão do FORPOREXT (SETEC/CONIF) propunha uma cartilha com diretrizes e orientações para a implantação dos Observatórios Locais do Mundo do Trabalho, conforme citação $n^{\circ} 8$.
} 
para fixar metas, rever o desempenho e facilitar a comunicação entre definidores de políticas, especialistas em determinadas áreas do conhecimento e para diversos interesses públicos (SHEN, 2011, p. 20).

A união ou cruzamento de vários indicadores forma os índices, como Índice de Desenvolvimento Humano (IDH), Índice de Desenvolvimento Educacional Brasileiro (IDEB). Os mesmos índices podem ser apresentados por diferentes fontes: Indicadores informados pelo Instituto Brasileiro de Geografia e Estatística ou o Atlas do Desenvolvimento Humano no Brasil, do Programa das Nações Unidas para o Desenvolvimento do Brasil (PNUD, 2013).

A variedade de indicadores necessita adaptação aos interesses dos pesquisadores e adaptação à realidade regional; pois os macro indicadores (nacionais ou estaduais) podem não revelar as realidades intra-regionais e locais ${ }^{10}$. Os indicadores, também, podem atender as diversas áreas do conhecimento ou setores socioeconômicos: como a Internacional Urban Sustentability Indicators List (IUSIL), que propõe 115 (cento e quinze) indicadores de análise distribuídos em 37 (trinta e sete) categorias e organizados em 4 (quatro) dimensões de desenvolvimento sustentável: ambiental, econômico, social e governamental (SHEN. 2011, p. 18). Por isso, podem focar áreas específicas, como educação (Global Index of Cognitive Skills and Educational Attainment) ${ }^{11}$; ou atender a uma questão particular, mas que atinge diversas regiões do mundo, como a migração (International Organization for Migration/OIM, 2014).

Alguns sistemas de indicadores são mantidos por organismos internacionais (PNUD/ONU); International Labor Organization/ILO). Outros são iniciativas e adaptações de interesse regional, como o Movimento "Nós Podemos Paraná", referente aos Objetivos do Desenvolvimento do Milênio (ODM) ${ }^{12}$. A manutenção e a sistematização dos indicadores podem ser realizadas pelo setor público nacional, como o Instituto Brasileiro de Geografia e Estatística - IBGE, no Brasil, e o Instituto Nacional de Estadística y Censos, na Argentina. Como também por interesse de governos regionais, como o Instituto Paranaense de Desenvolvimento Econômico e Social (IPARDES), no Paraná; a Fundação de Economia e Estatística/FEE, no Rio Grande do Sul; e o Instituto Provincial de Estadística y

\footnotetext{
${ }^{10}$ A Secretaria de Desenvolvimento Regional coordena a Política Nacional de Desenvolvimento Regional (PNDR) que visa articular ações de minimização dos hiatos macrorregional, subregional e intra-urbano. In: BRASIL. Secretaria do Desenvolvimento Regional. Premissas. Ministério da Integração Nacional. Disponível em: <http://www.integracao.gov.br/ premissas $>$.

${ }^{11}$ A entidade utilizou diversos indicadores para comparar 40 países. O Brasil foi classificado em penúltimo lugar nos índices de "cognitive skills $(-1,65)$ and educational attainment $(-2,01)$ "; perdeu apenas para a Indonésia. Mantido pela Fundação Pearson Education.

${ }^{12}$ Mantido pela Federação das Indústrias do Paraná, junto com o sistema S (SESI, SENAI, SENAC). Disponível em: <http://www.fiepr.org.br/nospodemosparana>.
} 
Censos de La Provincia de Misiones, na Argentina. Há do mesmo modo indicadores que são elaborados pela iniciativa privada, como o Instituto Brasileiro de Economia (IBRE), criado em 1951 e mantido pela Fundação Getúlio Vargas (FGV). Diferentes iniciativas, sejam públicas ou privadas ${ }^{13}$, garantem maior autenticidade das informações e menor possibilidade de manipulação dos dados; caso contrário, pode-se induzir o público a compreensões equivocadas da realidade ${ }^{14}$.

Por isso, os interessados em obter dados e informações devem ter critérios e propósitos claros para selecionar fontes e indicadores. Estes podem ser organizados em categorias, dimensões ou vertentes ${ }^{15}$, denominado de: economia, meio ambiente, trabalho, educação, governança, entre outros. Importa salientar que, apesar dos indicadores apresentarem-se de forma isolada - mensurados separadamente -, seja por meio numérico e estatístico, há interdependências profundas entre eles; sejam vistos na ótica das causas ou como consequências. Por exemplo: o Índice de Desenvolvimento Humano (IDH) é influenciado pelas variações dos indicadores de educação, trabalho, saúde. Deve-se considerar igualmente a diversidade em relação às fontes fornecedoras dos indicadores, se autônomas ou oficiais, se reconhecidas socialmente ou somente iniciativas pontuais. Ainda supõe-se a temporalidade - atualidade e frequência dos dados como critério de escolha dos indicadores. Isto é, faz-se necessária metodologia de escolha de fornecedores de indicadores, a fim de se obter qualidade e clareza nas informações.

$\mathrm{O}$ alcance e o reconhecimento do indicador em âmbito nacional e internacional auxiliam na formação das políticas públicas do país. Em equivalência, o próprio governo, por meio de seus diferentes Ministérios, tem a possibilidade de armazenar dados que, após processados e organizados por meio dos sistemas informacionais, formam o Knowledge Discovery Databases ou simplesmente banco de

\footnotetext{
${ }^{13}$ Várias instituições podem ter o mesmo interesse de análise, no caso da Responsabilidade Social no Ensino Superior, mas pertencerem a diferentes iniciativas sociais. In: HELLMANN, Gilmar. Indicadores para avaliar a responsabilidade social nas Instituições de Ensino Superior. IX Congresso Nacional de Educação (EDUCERE) - III Encontro Sul Brasileiro de Psicopedagogia. 26 a 29 de outubro de 2009. Anais... Curitiba: PUCPR. p. 5102-5103.

${ }^{14}$ Caso recente aconteceu com os dados de inflação PIB e outros na Argentina; incluindo advertência do FMI. In: SETTTI, Ricardo. Argentina: a mentira da inflação oficial e outros contos-do-vigário do governo de Cristina Kirchner. Coluna Vasto Mundo. 29/03/2013 as 16h00. Veja On-line. http://veja.abril.com.br/blog/ricardo-setti/vasto-mundo/argentina-amentira-da-inflacao-oficial-e-outros-contos-do-vigario-do-governo-cristina-kirchner/.

${ }^{15} \mathrm{Na}$ implantação do Observatório, o IFES do Rio Grande do Sul, propôs em sua metodologia a denominação de "vertentes" as dimensões de divisão dos indicadores, sendo: Setorial (estoque de emprego formal por setores do IBGE); Ocupacional (emprego formal por ocupações técnicas, escolaridade e faixa de remuneração da RAIS/TEM); e Educacional (número de matrículas e instituições de educação do MEC). Fonte: IFES/Rio Grande do Sul.
} 
dados públicos (SOARES JUNIOR, 2010). Num país com dimensões continentais como o Brasil, o governo federal tem estabelecido políticas parametrizadas em indicadores a fim de amenizar as severas desigualdades nacionais, regionais e intrarregionais.

No setor de planejamento educacional brasileiro, o Plano Nacional de Educação (PNE) levou em consideração tais diferenças regionais:

Todos os indicadores apontam para a profunda desigualdade regional na oferta de oportunidades educacionais e a concentração de população analfabeta ou insuficientemente escolarizada nos bolsões de pobreza existentes no País. Cerca de 30\% da população analfabeta com mais de 15 anos está localizada no Nordeste (PDE, p. 35).

Dentre os mil municípios com os menores IDEB, 80,7\% estão no Nordeste e, destes, $86 \%$ têm taxa de analfabetismo superior a $30 \%$.

Nesse caso, percebe-se que o conjunto de indicadores socioeconômicos referenciam propostas governamentais, como aponta o Índice de Desenvolvimento da Educação Básica (IDEB). Desta forma, o governo pode mensurar se há mudanças em sua atuação ou se necessita mudança de metas e de estratégias. Espera-se que a melhoria nos índices educacionais possa influenciar positivamente em outras áreas, como no mundo do trabalho, no desenvolvimento social etc.

A diversidade de iniciativas governamentais no setor educacional teve como consequência a formação da Rede Federal de Ensino Profissional, Científico e Tecnológico. Esta visa à expansão de formação de mão de obra qualificada para subsidiar as demandas emergentes dos setores produtivos do país, mas procurando atender as demandas regionais e locais. Neste contexto, surgem os Institutos Federais de Educação, Ciência e Tecnologia, organizados pela Lei $n^{\circ}$ 11.892/2008, formando uma rede de ensino que atendesse especialmente a formação tecnológica no Ensino Médio, mas também Ensino Técnico Superior. Os próximos tópicos fundamentam a ação dos Institutos Federais no contexto regional e local.

\section{A Rede Federal de Educação Profissional, Científica e Tecnológica (RFEPT)}

Os Institutos Federais de Educação, Ciência e Tecnologia ou IFETs foram criados pela Lei $\mathrm{n}^{\circ} 11.892$, de 29 de dezembro de 2008, transformando e integrando 31 (trinta e um) Centros Federais de Educação Tecnológica ou CEFETS, 75 (setenta e cinco) Escolas vinculadas às Universidades e Escolas Técnicas, também 
denominadas de Unidades Descentralizadas de Ensino (UNEDE), 39 (trinta e nove) Escolas Agrotécnicas, 7 (sete) Escolas Técnicas Federais e 8 (oito) Escolas vinculadas às Universidades; formando a Rede Federal de Educação Profissional, Científica e Tecnológica (RFEPT). Também integram a nova rede federal: 2 (dois) CEFETS, 25 (vinte e cinco) escolas vinculadas às universidades e 1 (uma) universidade tecnológica $^{16}$. Atualmente são 38 (trinta e oito) Institutos Federais presentes em todos Estados do Brasil, que podem ser definidos como: instituições de educação superior, básica e profissional, pluricurriculares e multicampi, são instituições autárquicas, detentoras de autonomia administrativa, patrimonial, financeira, didático-pedagógica e disciplinar, oferecendo ensino técnico médio integrado, concomitante e subsequente e cursos superiores de tecnologia e licenciaturas.

Simultaneamente à rede foi criado o Conselho Nacional das Instituições da Rede Federal de Educação Profissional, Científica e Tecnológica (CONIF); órgão que congrega todas as Instituições Federais de Educação Profissional, Científica e Tecnológica do Brasil. É uma instância de discussão, proposição e promoção de políticas de desenvolvimento da formação profissional e tecnológica, pesquisa e inovação. Além do conselho, os principais órgãos de assistência direta e imediata do Ministério de Educação ${ }^{17}$ que dão suporte político-administrativo para os IFETs são: a Secretaria de Educação Profissional e Tecnológica ou SETEC (Art. 13), a Diretoria de Desenvolvimento da Rede Federal de Educação Profissional e Tecnológica (Art. 14), a Diretoria de Políticas de Educação Profissional e Tecnológica (Art. 15) e a Diretoria de Integração das Redes de Educação Profissional e Tecnológica (Art. 16). Cabe à SETEC planejar, orientar, coordenar e avaliar o processo de formação e implantação da Política de Educação Profissional e Tecnológica do país. Nas atividades administrativas dos IFETs há diversas áreas e setores que mantém vínculo administrativo com outras instâncias governamentais além do Ministério da Educação.

Esse modelo de educação profissional e tecnológica integra o Plano de Expansão da Rede Federal fundamentado no Plano Nacional de Educação (PNE). De 1909 até 2002, foram construídas cento e quarenta (140) escolas técnicas no país. Entre 2003 e 2010, o Ministério da Educação entregou à população as 214 previstas no plano de expansão da RFEPT. Com outras 208 (duzentas e oito) novas escolas

\footnotetext{
${ }^{16}$ Esta universidade refere-se à UTFPR ou Universidade Tecnológica Federal do Paraná, a primeira especializada do Brasil. Proveniente da Escola de Aprendizes Artífices do Paraná, fundada em 1909, a instituição possui uma história centenária de formação e qualificação profissional tecnológica; o antigo CEFET-PR passou a ser Universidade por projeto de lei em 7 de outubro de 2005. Conta atualmente com 13 Campi espalhados pelo estado, sendo a sede na cidade de Curitiba.
}

17 BRASIL. Decreto Presidencial $\mathbf{n}^{\mathbf{0}} \mathbf{7 . 6 9 0}$ de 2 de março de 2012. Disponível em: <http://www.planalto.gov.br/ccivil_03/_Ato2011-2014/2012/Decreto/D7690.htm>. 
previstas até o final de $2014^{18}$ serão 562 (quinhentas e sessenta e duas) unidades que, em pleno funcionamento, gerarão aproximadamente 600 (seiscentas) mil vagas. A ampliação física e humana do atendimento da rede federal de ensino visa melhor atendimento às necessidades e diversidades regionais do país.

\section{O Instituto Federal de Educação do Paraná (IFPR)}

No Estado do Paraná, o Instituto Federal do Paraná (IFPR) traz uma herança centenária de ensino profissionalizante, proveniente de escolas que se transformaram ao longo do tempo, como a Escola Alemã (século XIX), o Colégio Progresso (século XX) e a Escola Técnica da Universidade Federal do Paraná (ET-UFPR). Além da Lei no 11.892 de criação também do IFPR, o Decreto $n^{\circ}$ 7.022, de 2 de dezembro de 2009, que estabeleceu medidas organizacionais de caráter excepcional para dar suporte ao processo de implantação da rede. Atualmente o IFPR possui 14 (quatorze) campi em funcionamento; 7 (sete) campi em fase de construção a serem consolidados em 2014, totalizando vinte (21) campi, distribuídos nas 10 (dez) regiões geográficas do Estado do Paraná. Também há previsão de 8 (oito) Campi Avançados e vinculados pedagógico e financeiramente ao Campus Sede mais próximo. No total o IFPR potencializará o acesso da população à educação profissional, científica e tecnológica, pública, gratuita e de qualidade, abrangendo no mínimo 50\% das 39 microrregiões políticas do Estado (BRASIL, 2008).

A interiorização do ensino tecnológico no Brasil, segundo Ferreira (2010), Ribeiro (2012) e Guimarães (2013), vive a maior e mais intensa expansão em sua história, visando atender as demandas nas macro e microrregiões dos estados brasileiros, influenciando o desenvolvimento regional nos índices educacionais, sociais, de trabalho, econômicos, entre outros. Por isso, torna-se importante relacionar a expansão dos IFETs com aspectos do desenvolvimento regional e local no tópico em sequência deste.

\footnotetext{
${ }^{18}$ De acordo com Dilma Rousseff, no programa semanal "Café com a Presidenta", que foi ao ar no dia 14 de março de 2014, até esta data já haviam sido abertas 152 unidades de institutos federais, continuando a meta de 208 até o final deste ano. In: BRASIL. Presidente promete prosseguir expansão da rede profissional. Pronatec. MEC. Segunda-feira, 24 de março de 2014, p. 14.
} 


\section{Os fundamentos dos IFETS no desenvolvimento regional}

A formação da Rede dos IFETs não é uma ação isolada do Ministério da Educação (MEC), mas integra-se como elemento de articulação no cenário educacional brasileiro. Segundo a Escola de Altos Estudos da CAPES ${ }^{19}$, o governo federal impulsionou educação promovendo vários programas de alcance nacional visando "otimizar dimensões do enlace entre a visão sistêmica de educação e desenvolvimento, que organiza, em torno da escola pública, ações na área da cultura, do esporte, dos direitos humanos e do desenvolvimento social." (PDE, p. 9; 43). Entre eles está a expansão e a interiorização do Ensino Superior Federal (RAMOS, 2014); simultaneamente a outras iniciativas no segmento educacional, como o Programa Mais Educação (DOU, 2007) ${ }^{20}$, Saúde na Escola, Conteúdos Digitais Educacionais, Caminho da Escola, Procampo, Projovem etc.

Portanto, o fomento político, pedagógico e financeiro do governo central no Ensino Profissional e Tecnológico integra ações do Planejamento e Orçamento Governamental, via Ministério da Educação. Este planejamento governamental está organizado em objetivos, iniciativas, programas e ações, que se concretizam nas unidades de gestão, como o IFPR $^{21}$, atendendo as necessidades na região de abrangência da instituição. $\mathrm{O}$ propósito institucional torna-se também parcela das "mãos do governo" na ação regional e local do Estado em função dos objetivos e metas propostas.

Os cursos oferecidos pelos IFETs visam qualificar parte do capital humano do país e alavancar a produção científica em várias áreas do conhecimento. $\mathrm{O}$ Catálogo Nacional de Cursos Técnicos (CNCT) (Ministério da Educação/CNCT) sugere uma relação de 220 (duzentos e vinte) cursos técnicos e 646 (seiscentos e quarenta e seis) cursos de qualificação profissional. Os cursos viabilizados pela RFEPT atendem atualmente os seguintes programas do Governo Federal: PRONATEC, Mulheres Mil, Rede Certific, Pró-Funcionário, PROEJA e e-Tec ${ }^{22}$.

${ }^{19}$ BRASIL, Decreto $\mathbf{n}^{\mathbf{0}} \mathbf{5 . 8 0 1}$, de oito de junho de 2006. Dispõe sobre a Escola de Altos Estudos, e dá outras providências. Presidência da República. Casa Civil. Disponível em: <http://www.planalto.gov.br/ccivil_03/_Ato2004-2006/2006/Decreto/D5801.htm>.

${ }^{20}$ Portaria Normativa Interministerial $\mathrm{n}^{\circ}$ 17, de 24 de abril de 2007. In: Diário Oficial da União (DOU). No 80, quinta-feira, 26 de abril de 2007. Secção 1. p. 5.

${ }^{21}$ Cada etapa do planejamento (meta, objetivo etc.) e unidade (ministério, instituição como IFPR) é identificada por um número, que por meio de sistemas eletrônicos (SIAFE, etc.) realizam a execução local e regional dos recursos planejados e repassados pelo governo central. In: Instituto Federal do Paraná. Plano de Distribuição Orçamentária. 2014, p. 26.

${ }^{22}$ Estes programas são viabilizados por meio de dois formatos estruturais dos IFETs: curso de qualificação profissional básica (FIC e PROEJA FIC) e curso técnico (Ensino Médio Integrado, Subsequente, Concomitante e PROEJA Integrado). In: Instituto Federal do Paraná. Itinerários Formativos do IFPR: dos cursos FIC à Pós-Graduação. Março 2014. Instituto Federal do 
Para implantação e execução dos cursos é imprescindível o conhecimento das demandas de mão de mão de obra do mercado regional e local. Além dos cursos, as atividades de pesquisa e extensão da instituição podem colaborar com a interação entre instituição e comunidades.

Um sistema de indicadores socioeconômicos pode balizar as demandas econômicas do contexto de atuação, mas também estabelecer, mensurar e acompanhar as mudanças sociais pretendidas pelo governo. Por isso a importância dos indicadores serem reconhecidos internacional e nacionalmente, respaldados tecnicamente e fundamentados por estudos e documentos institucionais, como a Lei de Criação dos IFETs. Tal documento ressalta 3 (três) características da inserção institucional no intuito do desenvolvimento regional: a) Territorialidade. "No território se materializa o desenvolvimento regional e local na perspectiva da sustentabilidade". Aos IFETs cabe colaborar com o desenvolvimento socioeconômico local e regional (art. $6^{\circ}$ ); focando a melhoria da qualidade de vida, a inclusão social e a construção da cidadania, viabilizados por meios científicos e tecnológicos (p. 36); espera-se como atitudes: ouvir e articular as demandas do território. Por isso, as instituições possuem autonomia para criação e extinção de cursos no limite de abrangência de sua atuação territorial (art. $2^{\circ}$ ). b) Finalidades dos IFETs. Estes podem ofertar educação profissional e tecnológica, em todos os seus níveis e modalidades, formando e qualificando cidadãos para atuação em diversos setores. Deve enfatizar um processo educativo e investigativo para soluções técnicas e tecnológicas que atendam às demandas sociais e peculiaridades regionais; resultando na geração de trabalho, de renda e na emancipação do cidadão. c) Estrutura organizacional. Estão organizados em formato multicampi, tendo autonomia na gestão dos recursos e nos investimentos; contudo, com identidade comum (SILVA, 2009). Pode-se dialogar com as políticas sociais e econômicas regionais e locais, respondendo aos anseios da comunidade, atendendo à vocação produtiva da região, incrementando arranjos produtivos existentes e promovendo os novos saberes (AZEVEDO, 2001). Espera-se formar indivíduos geradores de conhecimento (ensino), críticos, autônomos e que interajam com a comunidade (extensão). Assim, pretende-se melhorar as condições de vida local, resultando num desenvolvimento regional e local sustentável (HELLMANN, 2013) ${ }^{23}$.

No documento Plano de Desenvolvimento da Educação (PDE) do Plano Plurianual (PPA) do Governo Federal, para os anos de 2012 a 2016, os IFETs são

Paraná. Documento que disciplina processo de Reconhecimento de Saberes e Competências no IFPR são encaminhadas ao MEC. Reitoria. Notícias. Friday, 28 de March de 2014 - 4:55 PM.

${ }^{23}$ Para haver desenvolvimento regional faz-se necessário o crescimento e o desenvolvimento econômico sustentável. Esta relação pode ser melhor compreendida no capítulo 3, item 4: "Crescimento e Desenvolvimento Econômico Sustentável”. In: HELLMANN, Gilmar, 2013. Op. Cit. 
destaques no desenvolvimento regional e local da educação básica. Na visão do PDE, estas instituições formam rede de relações; atuam em diferentes modalidades de ensino de forma "integrada e referenciada regionalmente, evidenciando com grande nitidez os desejáveis enlaces entre educação sistêmica, desenvolvimento e territorialidade." (PDE 2012-2016, p. 32), especialmente nas "cidades-polo". Especifica a ação local:

[...] a) constituindo-se em centros de excelência na oferta do ensino de ciências, voltado à investigação empírica, como apoio as escolas públicas; b) oferecendo programas especiais de formação pedagógica inicial e continuada, com vistas à formação de professores para a educação básica, sobretudo nas áreas de física, química, biologia e matemática, de acordo com as demandas de âmbito local e regional; c) e oferecendo programas de extensão, dando prioridade à divulgação científica (PDE 2012-2016, p. 31).

Acrescenta a orientação que o "resultado" esperado da atuação dos cursos na regionalidade deve "estimular a produção cultural, o empreendedorismo e o cooperativismo... a partir de processos de autogestão." (PDE 2012-2016, p. 32).

No Termo de Acordo de Metas (TAM), assinado pelos IFETs com a SETEC/MEC, em 2010, enfatizou-se que estas instituições...

[...] devem atuar como agentes colaboradores na estruturação das políticas públicas para a região que polarizam, estabelecendo uma interação mais direta junto ao poder público e às comunidades $\mathrm{e}$ representações locais e regionais, significando maior articulação com os arranjos produtivos, sociais e culturais; a necessidade da diversificação da oferta de cursos, especialmente os inovadores, sintonizados com as demandas que contribuam para o desenvolvimento local e regional e, consequentemente, a sua adequação aos Catálogos Nacionais de Cursos Técnicos, Superiores de Tecnologia e demais catálogos nacionais (MEC/IFET, Termo...).

O documento reforça aspectos anteriormente citados, mas especifica diretrizes para a execução de suas atividades regionais: garantia de matrículas num percentual de 50\% (cinquenta por cento) para o ensino técnico de nível médio e de vinte (20\%) para cursos de licenciaturas e de formação de professores; oferta de Cursos Técnicos e de Formação Inicial e Continuada/FIC para o PROEJA ${ }^{24}$; e

\footnotetext{
${ }^{24}$ Meio de inclusão regional segundo o Decreto de $\mathbf{n}^{\mathbf{0}} \mathbf{5 . 8 4 0}$ de 13 de julho de 2006. Institui, no âmbito federal, o Programa Nacional de Integração da Educação Profissional com a Educação Básica na Modalidade de Educação de Jovens e Adultos - PROEJA, e dá outras providências.
} 
apresentação de projetos por Campus, que visem à melhoria da qualidade da educação básica na rede pública, especialmente em apoio ao ensino médio inovador ${ }^{25}$.

Ainda em nível de Ensino Médio, os IFETs são importantes viabilizadores de programas do governo federal, como o Programa Nacional de Acesso ao Ensino Técnico e Emprego, ou Pronatec ${ }^{26}$, lançado em 28 de abril de 2011. Considerado pela presidente do Brasil um marco na história do ensino técnico e da qualificação profissional no país, até o primeiro bimestre de 2014 o Pronatec já havia beneficiado aproximadamente 4,6 milhões de pessoas em mais de 3.200 municípios brasileiros. Para efetivação do programa há dois agentes importantes: a) Demandantes - coordenam, mobilizam e selecionam o público-alvo para matrícula; elaboram e enviam material de apoio. b) Ofertantes - ofertam os cursos, realizam a assistência do aluno e confirmam a matrícula e a frequência. Os ofertantes são a RFEPT, os IFETs, os Serviços Nacionais de Aprendizagem (Sistema S) e as Redes Estaduais de Educação Profissional e Tecnológica - a partir de 2012 (MEC-PRONATEC, 2011). Por isso, é importante promover as parcerias público-público e público-privada para não haver sobreposição regional na oferta de cursos e de recursos federais para a mesma finalidade.

Os IFETs são autarquias federais de atuação também no Ensino Superior, "congênere" às universidades, como denomina a Lei 11.892/2008. Portanto, os Institutos Federais e demais Instituições de Ensino Superior (IES) públicas e privadas tornam-se responsáveis socialmente (HELLMANN, 2009) pela formação do capital humano regional nas áreas de ensino, pesquisa e extensão, conforme já preconizava a Lei de Diretrizes e Bases da Educação:

Art. 52. As universidades são instituições pluridisciplinares de formação dos quadros profissionais de nível superior, de pesquisa, de extensão e de domínio e cultivo do saber humano, que se caracterizam por: I produção intelectual institucionalizada mediante o estudo sistemático dos temas e problemas mais relevantes, tanto do ponto de vista científico e cultural, quanto regional e nacional (LDB 9394/96).

Presidência da República. Casa Civil. Disponível em: <http://www.planalto.gov.br/ ccivil_03/_ato2004-2006/2006/decreto/D5840.htm>.

${ }^{25}$ Essa era a meta inicial em 2011; nos anos seguintes, a proposta seria a ampliação de $10 \%$ ao ano, em parceria com a rede publica de ensino.

${ }^{26}$ O PRONATEC possui três eixos de atuação: oferta de ensino técnico para quem está cursando o Ensino Médio; cursos de qualificação profissional para o jovem ou o adulto que deseja formação profissional; e cursos que aumentem as chances de trabalho e remuneração para as pessoas que estão no programa Brasil sem Miséria. In: ROUSSEF, Dilma. O PRONATEC será fator de organização da oferta de formação e capacitação profissional. Blog do Planalto. 28 de abril, 2011. 
A mesma lei orienta quanto à forma democrática de gestão, salientando sua inserção regional e local:

Art. 56. As instituições públicas de educação superior obedecerão ao princípio da gestão democrática, assegurada à existência de órgãos colegiados deliberativos, de que participarão os segmentos da comunidade institucional, local e regional (LDB 9394/96).

Como visto anteriormente, a LDB justifica e incita os IFETs na realização de atividades de pesquisa e de extensão; na estrutura institucional estas atividades são coordenadas pelo setor com status de Pró-Reitoria. Destarte, espera-se sintonia administrativa e pedagógica entre métodos e conteúdos de ensino e o desenvolvimento das atividades de pesquisa e extensão; segundo a epistemologia do pensamento deweyniano (GASQUE, 2011) e os pilares da educação mundial: “aprender a conhecer, fazer, ser e conviver." (DELORS, p. 93). Isto possibilita aos docentes, discentes e técnicos maior inserção e interatividade com a comunidade local. Em consequência, a força comum da estrutura da rede de educação tecnológica possibilita a construção da identidade regional dos IFETs.

Isso posto, a criação do Observatório Regional nos IFETs pode auxiliar na parametrização e mensuração das atividades de ensino, pesquisa e extensão. Como produto de sua atuação institucional, o Observatório poderia responsabilizar-se por: organização de indicadores socioeconômicos regionais e locais das unidades do IFET; o fomento e a atualização de dados e informações socioeconômicas no site institucional; a criação de periódico institucional socializando a produção de conhecimento cientifico; e a realização de fóruns locais de discussão referente aos assuntos de desenvolvimento regional.

Para que os IFETs efetivem as diretrizes e anseios fundamentados, faz-se necessário que as unidades incluam o tema do desenvolvimento regional e local no planejamento interno, conferindo-lhe identidade própria. A principal ferramenta das instituições de ensino federal que dispõe sobre as políticas e a diretriz de atuação institucional denomina-se Plano de Desenvolvimento Institucional (PDI). Além deste, outros documentos instrucionais são ferramentas de gestão imprescindíveis ao planejamento institucional. Tema esse que será abordado no próximo tópico.

\section{Planejamento institucional e desenvolvimento regional}

Desde a publicação da LDB em 1996, a organização político-pedagógica das instituições federais e privadas de ensino vem se aperfeiçoando paulatinamente. $\mathrm{O}$ 
governo central orienta a formulação de documentos institucionais que estabeleçam elementos comuns à administração central do MEC, mas também que desenvolvam identidade regional e local. $\mathrm{O}$ Plano de Desenvolvimento Institucional (PDI) é o principal documento institucional: "consiste num documento em que se definem a missão da instituição de ensino superior e as estratégias para atingir suas metas e objetivos." (MEC) ${ }^{27}$. Desde a formulação da LDB, um histórico legal (Art. 16, Decreto $N^{o} 5.773 / 2006$ ) de portarias, resoluções e pareceres maturaram a estrutura do PDI, que resultou num documento "conciso e claro, contendo dados e informações relevantes para a análise de mérito da proposta e que permitam também, tanto à IES como ao MEC, identificar e monitorar o cumprimento das metas institucionais estabelecidas." (MEC, 2007). O PDI é elaborado nos primeiros cinco anos da instituição permitindo construção participativa, exercício de criatividade, articulação entre ações, qualidade e orçamento institucional "possibilitando comparar, para cada um, a situação atual e futura (após a vigência do PDI)". Os dados e informações sobre a IES organizam-se em três níveis hierárquicos: dimensões, categorias de análise e indicadores. Segundo a Lei no 10.861/2004, ou Sistema Nacional Avaliação do Ensino Superior (SINAES), o PDI...

[...] identifica o projeto e/ou missão institucional, em termos de finalidade, compromissos, vocação e inserção regional e/ou nacional... refere à sua contribuição em relação à inclusão social, ao desenvolvimento econômico e social, à defesa do meio ambiente, da memória cultural, da produção artística e do patrimônio cultural... inclui outros itens considerados relevantes para a instituição tendo em vista a compreensão e construção da sua identidade institucional, suas especificidades e sua missão (hospitais, teatros, rádios, atividades artísticas, esportivas e culturais, inserção regional, entre outros) (Art. $3^{\circ}$, \& III, Lei $\left.\mathrm{N}^{\mathrm{o}} 10.861 / 2004\right)$.

O PDI dos IFETs descreve a identidade comum da RFEPT - lei de criação e estrutura básica - mas, confere a cada um a identidade de interação com o contexto local e regional. A implementação e o controle da oferta das atividades educacionais a que se propõe exigem planejamento criterioso e intencional voltado para o cumprimento de sua função social (IFRF, PDI, 2013).

Nos IFETs o Observatório Regional pode contribuir para a construção do PDI, aproximando o projeto institucional da realidade local; tanto quanto ser ferramenta de gestão ao monitorar os índices de desenvolvimento socioeconômico regional e local.

27 MEC. Formulário do Plano de Desenvolvimento Institucional. Disponível em $<$ http://www2.mec.gov.br/sapiens/Form_PDI.htm>. 


\section{O desenvolvimento regional no IFPR}

$\mathrm{Na}$ primeira versão do Plano de Desenvolvimento Institucional (PDI) do IFPR, o tema do desenvolvimento regional e local foi citado como parte de um objetivo da Pró-Reitoria de Ensino, Pesquisa e Extensão: "Incentivar o desenvolvimento de projetos de extensão vinculados ao desenvolvimento regional e envolvendo professores e alunos" (IFPR. PDI, 2013, p. 26). Na fase atual, o PDI está no estágio de revisão e reelaboração. Neste documento, o estudo identificou algumas menções em relação ao tema. Estas se referem ao tópico do planejamento do Campus, no qual 3 (três) delas mencionaram os termos "desenvolvimento local e regional" no planejamento de suas atividades. a) O Campus Palmas menciona a necessidade de "metodologia para abertura e manutenção de cursos obedecendo às demandas de desenvolvimento local e regional, conforme lei dos IFETs e estatuto do IFPR.” (BRASIL, 2011, p. 27). Tal metodologia resultaria em estudos, pesquisas diagnósticas e mapeamento das potencialidades regionais e locais, em nível produtivo, social e cultural. b) No Campus União da Vitória o "atendimento das demandas de desenvolvimento local e regional" se refere aos mesmos itens anteriormente citados; e acrescenta a participação no desenvolvimento de projetos de pesquisa e extensão, envolvendo a comunidade interna e externa do Campus; e na realização de parcerias com empresas e instituições regionais e locais. c) $\mathrm{O}$ Campus Colombo reforça o mesmo tópico: "atendimento das demandas de desenvolvimento regional e local na abertura de cursos técnicos e superiores no Campus, mapeando as potencialidades e vocações locais, tanto em nível produtivo, social e cultural". Percebe-se alguma evolução entre a primeira versão do PDI e a atual.

Outro aspecto do PDI refere-se ao eixo da avaliação e acompanhamento do desenvolvimento institucional; neste item a instituição deve descrever a metodologia, as dimensões e os instrumentos de avaliação das atividades acadêmicas de Ensino, Pesquisa e Extensão, de Planejamento e de Gestão. No caso do IFPR, estas ferramentas podem ser: o Planejamento Estratégico (PE), o Plano de Diretrizes Orçamentárias (PDO) e os Relatórios de Autoavaliação Institucional. O Observatório Regional poderia ser ferramenta estratégica e de acompanhamento daquelas citadas.

No Planejamento Estratégico $(\mathrm{PE})^{28}$ do IFPR o desenvolvimento regional caracterizou-se pela revisão da missão, visão e valores institucionais. Deste documento salientam-se as seguintes referências correlacionadas ao desenvolvimento regional: "visando à formação de cidadãos críticos, autônomos e empreendedores, comprometidos com a sustentabilidade" (missão);

\footnotetext{
${ }^{28}$ O Planejamento Estratégico do IFPR foi implementado pela Portaria $\mathbf{n}^{\mathbf{0}} \mathbf{4 3 6}$, de 17 de agosto de 2012, instituindo o Comitê Estratégico Central do Instituto Federal do Paraná (COMEC).
} 
"reconhecimento pelo compromisso com a transformação social" (visão); e acreditando na sustentabilidade, na diversidade humana e cultural, na inclusão social, no empreendedorismo e respeito às características regionais (valores). Entretanto, o documento não detalha a aplicação destes aspectos no desenvolvimento regional e local das comunidades onde o IPFR está ou se fará presente. No PE deveria haver elementos que evidenciassem as potencialidades e as dificuldades da organização (ambiente interno); e a análise contextual (ambiente externo) das oportunidades e ameaças na relação instituição e desenvolvimento regional $^{29}$. Afinal, a organização existe numa complexa e diversificada rede de forças ambientais, como fatores políticos, econômicos, legais, tecnológicos, sociais, entre outros. Compreender este macroambiente é elemento chave para uma boa prestação de serviços institucionais à comunidade e a potencialização dos recursos utilizáveis na geração atual e disponíveis para as futuras gerações; esta é uma das características da sustentabilidade. Por conseguinte, o planejamento sustentável compreende o homem como "causa, senhor ou sujeito diante da natureza; ou como resultado, consequência ou objeto da natureza." $\left(\right.$ HELLMANN, 2013) ${ }^{30}$. No entanto, para planejar (PE) é necessário estar referenciado $(\mathrm{PDI})$.

Outro documento utilizado pelo IFPR é o Plano de Distribuição Orçamentária (PDO). Neste, o desenvolvimento regional restringe-se à participação democrática da comunidade interna da instituição. A adaptação orçamentária às características locais das unidades ficou sob a responsabilidade dos seus gestores, tanto na previsão quanto na aplicação dos recursos. Isto, talvez, se deve ao fato do orçamento envolver gestão (previsão), acompanhamento (supervisão) e aplicação dos recursos (execução), orientados por procedimentos legais e temporais, previamente estabelecidos.

Tanto o PDE quanto o PDO estão insertos numa realidade dinâmica, portanto, é imprescindível que a organização esteja sensibilizada para ajustes constantes destes documentos, em que poderia rever a participação do IFPR no desenvolvimento regional (IFPR, Observatório, Campus Pitanga, 2013, p. 25). Vários ajustes são influenciados pelo Plano Plurianual, a Lei de Diretrizes Orçamentárias (LDO) e a Lei de Orçamentos Anuais (LOA) do Governo Federal.

Enquanto o IFPR vai expandindo e lapidando sua identidade, as ações realizadas são apresentadas às instâncias superiores do MEC por meio dos Relatórios de Autoavaliação Institucional, realizados anualmente. Enquanto os documentos de planejamento institucional carecem de aspectos do desenvolvimento regional, os relatórios institucionais retratam varias atuações da instituição neste tópico.

\footnotetext{
${ }^{29}$ Sugere-se a aplicação da metodologia de administração SWOT.

${ }^{30}$ A questão da sustentabilidade pode ser melhor compreendida no item "6.5 e) Sustentabilidade Ambiental”. In: HELLMANN, Gilmar. 2013. Op. Cit.
} 
No relatório do IFPR de 2010 (IFPR, 2011) destacou-se o desenvolvimento regional em relação: a) a inserção regional ocorre ao situar-se os Campi nos polos microrregionais $^{31}$ do Estado, conforme classificação IPARDES; b) a finalidade institucional fomenta o desenvolvimento socioeconômico local, regional e nacional conforme Lei $\mathrm{N}^{0} 11.892 / 2008$; c) as ações do Campus consideram o exercício do ensino como desenvolvimento local, regional e da territorialidade; d) as atividades de Pós-Graduação levam os discentes e docentes a participar de eventos regionais e locais; e já realiza produção cientifica institucional tecnológica regional (p. 31); e) as ações de pesquisa e de pós-graduação (projetos e grupos) visam à interação e ao aumento da inserção regional (pg. 40); f) a política de acesso evidencia as demandas sociais com vistas ao desenvolvimento local e regional, tendo efetivas ações institucionais nas potencialidades regionais. No relatório de 2011, recordou-se o objetivo institucional ao "estimular processos educativos que levem a geração de trabalho e renda e emancipação do cidadão na perspectiva do desenvolvimento socioeconômico local e regional". Cita ainda que a oferta de graduação está de acordo com as necessidades e tendências do mundo do trabalho, dos arranjos produtivos, culturais e sociais, considerando contextos regionais e locais, identificando através de estudos e pesquisas do mundo do trabalho, de fóruns de desenvolvimento regional, de Eixos Tecnológicos e outros instrumentos pertinentes. E, por fim, a instituição vem promovendo eventos estudantis com abrangência e relevância regional. No relatório de 2012 salientouse que a inserção regional e local se dá com o Projeto de Expansão da RFEPT e a implantação dos novos Campi e Campus Avançado.

O escopo final destas ferramentas de gestão, comentadas neste tópico, é cumprir plenamente a missão institucional, sendo eficiente e eficaz com os recursos disponibilizados para a execução das atividades, e o efetivo auxilio no crescimento e desenvolvimento local e regional. Neste caso, o Observatório Regional pretende contribuir com a gestão estratégica, subvencionando dados e informações, em forma de indicadores e índices que subsidiem os gestores nas tomadas de decisão. A implantação do Observatório Regional, a utilização de indicadores socioeconômicos e a proposição de metodologia de ação são os tópicos a serem tratados na sequência.

\section{A implantação do Observatório Regional do Paraná no IFPR}

Até este ponto foram apresentados os fundamentos e o contexto do Observatório Regional; neste tópico detalha-se o projeto do mesmo no IFPR. Também se

31 A divisão de microrregiões e mesorregiões no Estado do Paraná segue definição do IPARDES. 
relacionam os possíveis problemas em que o Observatório poderia auxiliar nas resoluções, os propósitos de sua criação (objetivos), a proposição de metodologia e etapas de trabalho, os indicadores a serem utilizados e os produtos que podem ser disponibilizados, tanto para a comunidade interna da instituição, quanto para a população externa interessada; já que se trata de atividade no âmbito do setor público.

A principal ferramenta do Observatório são os indicadores, um produto intangível que necessita ser transformado em soluções factíveis. Contudo, os dados socioeconômicos que sustentam os indicadores encontram-se dispersos em bancos de informações, em sítios institucionais e em diversos informativos públicos e privados. O Observatório propõe-se a consolidá-los numa estrutura lógica, adaptada ao contexto institucional, e numa linguagem que favoreça a compreensão dos usuários; atento à cientificidade e as técnicas acadêmicas. A ausência de critérios e metodologia na utilização dos indicadores poderia asseverar o distanciamento entre o ideal da missão e a realidade do contexto institucional. Para diminuir tal hiato detalham-se alguns tópicos do projeto de implantação do Observatório Regional do IFPR.

\section{Problemas do Observatório Regional}

Os IFETs são instituições autárquicas, detentoras de autonomia administrativa, patrimonial, financeira e didático-pedagógica. Cabe a cada unidade e/ou gestão utilizar estratégias de implantação e/ou renovação dos cursos técnicos de nível médio e superior ${ }^{32}$. Não obstante, quando há preponderância de diretrizes políticas sobre os critérios técnicos, as decisões podem ser tácitas e desvinculadas do planejamento. Isso resultaria em: proposição de cursos sem público alvo selecionado; retrabalho administrativo; má aplicação dos recursos públicos; subaproveitamento, carência ou inadequação de infraestrutura; recursos humanos ociosos, descontextualização formativa da mão de obra; identificação empírica da realidade do mercado de trabalho local e regional; conflito entre políticas públicas com o mesmo fim; descontinuidade de projetos públicos comprometendo programas governamentais no setor educacional; entre outros. Enfim, a instituição acaba não atendendo sua missão nas demandas do desenvolvimento regional. Tais desafios institucionais exigem visão holística do contexto ad intra e ad extra da instituição. Os indicadores monitorados pelo Observatório Regional tornam-se fonte preciosa de informação ao sincronizar ações administrativas e pedagógicas

\footnotetext{
${ }^{32} \mathrm{O}$ documento que apresenta a implantação dos cursos no IFPR é denominado de Itinerário Formativo.
} 
institucionais com as demandas regionais. Neste sentido, o próximo item apresenta os principais propósitos do projeto.

\section{Objetivos do Observatório Regional}

a) Objetivo geral: Coletar, organizar e sistematizar indicadores que possibilitem a análise socioeconômica do contexto do IFPR, auxiliando a gestão geral e a das unidades institucionais na otimização dos recursos públicos e contribuindo com o desenvolvimento regional e local no âmbito do estado do Paraná.

b) Objetivos específicos: Programar os objetivos do Observatório do Mundo do Trabalho no âmbito do IFPR; Ampliar a aquisição de dados contextuais do IFPR para melhor interação deste com a RFEPT; Atualizar dados quantitativos e qualitativos provenientes de órgãos governamentais e oficiais de forma estruturada e sistematizada para o IFPR; Contextualizar os dados coletados, organizando-os em informações relevantes para o contexto regional e local; Selecionar fontes geradoras de dados atualizados e organizá-los em dados informacionais ao IFPR; Disponibilizar informações políticas, econômicas, sociais, tecnológicas e ambientais do contexto regional e local para análise da instituição, possibilitando aos gestores conhecer pontos fracos e fortes do IFPR; Oportunizar aos gestores do IFPR indicadores para a análise do ambiente externo à instituição, percebendo ameaças e oportunidades no macro e micro contexto; Subsidiar as unidades e setores administrativos do IFPR para a elaboração de projetos de consolidação e expansão da RFEPT; Auxiliar na priorização de investimentos financeiros, econômicos, em pessoas e de temporalidade do planejamento estratégico do IFP; Elaborar parâmetros de mensuração de metas e operacionalização de táticas do planejamento estratégico das unidades do IFPR; Promover a ampliação das atividades do Observatório nas Unidades do IFPR.

\section{Metodologias do Observatório Regional}

Coleta, organização e sistematização de indicadores que possibilitem a análise socioeconômica do contexto do IFPR, com o intuito de auxiliar na gestão geral e das unidades institucionais na otimização dos recursos públicos e contribuindo com o desenvolvimento regional e local no âmbito do Estado do Paraná.

Considerando que o projeto situa-se na área de ciências sociais e aplicadas, que nas fases de pesquisa, organização e interpretação dos dados, considere-se a visão do pensamento complexo; ou seja, não se restringe a uma única ciência: 
[...] as ciências cognitivas devem ser compreendidas como o estudo da inteligência humana, indo de sua estrutura formal e de seu substrato biológico, passando por sua modelagem, até suas expressões psicológicas, linguísticas e antropológicas [...] envolvendo várias disciplinas como "a psicologia cognitiva, a epistemologia, a filosofia, a semiótica, a linguística, a biologia e a neurofisiologia, e a inteligência e a vida artificiais", bem como a matemática, a história e a geografia (SILVA, C. 2004, p. 5-6).

Por parte daqueles que utilizam os produtos do Observatório consideram-se algumas premissas: ter o desenvolvimento humano como centro dos interesses, sendo realizado por meio da formação de capital social e competências locais; o crescimento econômico não tem fronteiras, sendo que a produção local tem se mostrado melhor escudo para as crises globais; o fortalecimento regional acontece ao se formar redes produtivas (arranjos, cadeia e sistemas); a diversidade de iniciativas governamentais exige parceria público-público (municipal, estadual e nacional) e público-privada (IFPR, 2013 p. 8).

Quanto à cientificidade do trabalho não se pode negligenciar os preceitos cartesianos. O segundo (preceito), dividir cada uma das dificuldades que eu houvesse de examinar em tantas parcelas quantas pudessem ser e fossem exigidas para resolvê-las melhor. O terceiro (preceito), conduzir por ordem meus pensamentos, começando pelos objetos mais simples e fáceis de serem conhecidos, para subir a pouco e pouco como por degraus até o conhecimento dos mais compostos, e supondo mesmo certa ordem entre os que não precedem naturalmente uns aos outros. E o último, fazer por toda a parte numerações tão completas e revistas tão gerais, que ficasse certo de nada omitir (PAULI, 1997).

O modus operandi do método cartesiano significa que "compreender algo é compreender a sua causa", e que, portanto, todo o algo que se pretenda compreender deve ser considerado como efeito. Quando contextualizados, os indicadores quantitativos e qualitativos induzem a este tipo de interpretação. Todavia, a correlação causa-efeito possui interferências de intencionalidade, de vontade e de interesses variados; isto pode limitar ou ampliar as possibilidades de aplicação.

Em relação à contextualização das informações, à socialização e à partilha com as unidades interessadas, utilizar a metodologia de Investigação Apreciativa (IA) ${ }^{33}$.

\footnotetext{
${ }^{33}$ No estado do Paraná esta metodologia é utilizada pela FIEP na construção de Projetos para realização dos Objetivos do Milênio e na construção de cenários e perspectivas para o mercado de trabalho. A metodologia foi criada nos Estados Unidos pelos professores David Cooperrider e Ronald Fry, da Case Western Reserve. É utilizado Global Fórum, orientando os grupos na organização de seus processos criativos e no planejamento de suas ações. A metodologia trabalha com os princípios de construtivismo, simultaneidade, interpretação poética, antecipação de futuro e abordagem positiva de mudança.
} 
Esta metodologia possui suas raízes no saber socrático ${ }^{34}$; o qual concebe o interlocutor como artífice da verdade mediante uma série de perguntas, as quais intuem no arguidor algumas respostas. Ainda no processo de coleta, contextualização e interpretação dos dados é importante considerar a metodologia de Análise de Discurso. Esta considera que na comunicação a linguagem, o discurso e a argumentação sofrem interferências da ideologia, do poder e do ponto de vista de seus enunciadores.

Por fim, para organizar dadas informações e aplicá-las no contexto regional e local, os métodos SWOT ${ }^{35}$ e PEST-A ${ }^{36}$ são frequentemente utilizados em estudos que envolvam a administração e a economia. Kotler $(2000)$ define a metodologia SWOT como a "avaliação global das forças e fraquezas, oportunidades e ameaças" de uma empresa, organização ou setor; com a sua aplicação, pretende-se verificar as relações espaciotemporais da instituição permitindo estabelecer rumos e diretrizes para a mesma. Já o método PEST-A divide o ambiente geral em cinco áreas, definindo uma visão didática das influências externas exercidas sobre a organização, tanto no tempo presente como para o futuro (SILVA, S., 2005).

\section{Etapas do trabalho do Observatório Regional}

Para que o trabalho do Observatório tenha interação entre a unidade central (Reitoria) e as unidades locais (Campus) propõe-se que as ações observem o seguinte processo: a) pesquisa de dados e informações sobre a região em estudo (pesquisa em agências e instituições, pesquisa local); b) realização de fórum de discussão local sobre o estudo, esclarecendo o papel do IFPR e identificando potencialidades locais; c) organização de Observatório Local para discussão, atualização e contextualização das informações; d) estabelecimento de prioridades de ação ad intra e ad extra ao IFPR (IFPR, 2013 p. 8).

\footnotetext{
${ }^{34}$ Também é denominado de arte de maiêutica ou arte de parir as ideias.

${ }^{35}$ SWOT é um acrônimo formado pelas iniciais das palavras Strengths, pontos fortes; Weaknesses, pontos fracos; Opportunities, oportunidades, e Threats, ameaças. Este método foi elaborado pelo norte-americano Albert Humphrey, durante o desenvolvimento de um projeto de pesquisa na Universidade de Stanford, entre as décadas de 1960 e 1970. In: BARROSO, Antônio C. O.; DIDIO, Robert J. Uma reflexão sobre estratégias, competitividade e conhecimento. Revista Eletrônica PRODAM Tecnologia. Ed. 2, Ano 2, abril/maio/junho, 2009.

${ }^{36}$ O método PEST-A é um acrônimo que representa cinco fatores de análise: político, econômico, social, tecnológico e ambiental.
} 


\section{Indicadores do Observatório Regional}

Entre tantos índices e indicadores disponibilizados nas mídias atuais, o Observatório Regional do IFPR já pode disponibilizar os indicadores abaixo relacionados; eles foram distribuídos em 5 (cinco) categorias. Estas atendem as necessidades básicas de ensino do Instituto; contudo, pode-se ampliar as categorias e os indicadores de acordo com as necessidades específicas das unidades (Campus) e conforme a demanda das atividades de pesquisa e extensão.

a) Geográfica: área em $\mathrm{Km}^{2}$, distância do Campus da Reitoria e entre Campus e Campus Avançado em quilômetros, principais vias de acesso, localização geográfica e política (Meso e Microrregião).

b) Populacional: taxa de crescimento geral, taxa de crescimento urbano, taxa de crescimento rural, população estimada, pirâmide populacional, densidade populacional rural e urbana, grau de urbanização, população economicamente ativa e população em idade ativa.

c) Educacional: matrículas totais, do ensino médio, de cursos médios profissionalizantes concomitantes e subsequentes, de programas como Pronatec, da educação de jovens e adultos, ensino superior, EAD e presenciais. Cursos Superiores, considerando Licenciatura, Bacharelado, Tecnológico, vagas oportunizadas, cursos ativos ou extintos, ensino público ou privado.

d) Econômica: valor adicionado bruto (VAB), valor adicionado bruto por setor econômico, variação entre períodos, valor adicionado fiscal (VAF): primário, indústria e comércio e serviços, simples da indústria, simples do comércio e serviços; atividade primária: a) por tipo de propriedade, b) por atividade, c) por produto, d) rentabilidade, e) área ocupada; formação de APLs e outras organizações econômicas; consumo de energia por setor econômico: a) consumo, b) consumidores, c) e variação entre períodos. Intersecção de indicadores populacional, educacional e econômico: índice de desenvolvimento humano, ocupação das pessoas por atividade econômica, produto interno bruto per capita, formação educacional da população economicamente ativa. Intersecção de indicadores econômicos e sociais: secção e subsecção econômica CNAE do município sede, por participação econômica, estabelecimentos, numero de empregos e PEA.

e) Sustentabilidade: socioambientais, taxa de poluição, área de preservação, doenças comuns etc.

$\mathrm{Na}$ categoria geográfica, populacional, educacional e econômica os dados dos indicadores são encontrados para todas as unidades do IFPR. Na categoria 
sustentabilidade (IPARDES, 2013) ${ }^{37}$, não há muitos indicadores e não se encontram dados para todas as localidades das unidades do IFPR.

\section{Inovação no Observatório Regional}

Além de atender aos objetivos propostos no projeto acredita-se que o trabalho do Observatório Regional possibilitará: aumento no preenchimento de vagas ofertadas por cursos; diminuição da evasão de alunos no decorrer do curso; ampliação do número de cursos por Campus, otimizando a capacidade física da unidade; foco nos eixos de conhecimento; expansão ou interiorização do IFPR com maior eficácia e eficiência regional; acréscimo na participação do IFPR na matriz orçamentária do CONIF em termos de expansão e número de alunos; auxílio no Planejamento Estratégico das unidades.

Estes resultados são esperados em virtude das seguintes circunstâncias: aplicação imediata do Observatório no âmbito desta autarquia federal; a RFEPT está em fase de expansão com apoio em diversas instâncias públicas (órgãos e ministérios); a metodologia pode ser replicada em outros IFETs do país; necessidade deste tipo de atividade; muitos cursos com perfis modernos e mão de obra focada em segmentos do mercado de trabalho; no Brasil há várias instituições públicas e privadas que subsidiam os dados e informações; os dados primordiais são públicos, gratuitos e estão disponíveis na rede mundial de computadores; a metodologia é passível de ser aplicadas em instituições públicas e privadas, respeitando os interesses e objetivos de cada setor; no Estado do Paraná muitos indicadores são disponibilizados pelo IPARDES e pela FIEP; a metodologia auxilia no planejamento governamental federal, regional e municipal; os custos de implementação da metodologia são bastante modestos em relação à pujança dos benefícios.

\section{Produtos do Observatório Regional}

Considerando a disponibilidade de recursos humanos e temporais possibilitados pelo IFPR para o trabalho do Observatório, seria possível oferecer os seguintes

\footnotetext{
${ }^{37}$ Nesta categoria o IPARDES lançou em dezembro de 2013 um estudo utilizando como limite geográfico as bacias hidrográficas do estado e não por municípios ou região política. In: IPARDES. Indicadores de desenvolvimento sustentável por bacias hidrográficas do Estado do Paraná. Curitiba: IPARDES. 2013.
} 
produtos: a) Formatação de periódico no formato Boletim Informativo ${ }^{38}$; b) Oferta, manutenção e atualização de Banco de Informações por Campus e por regiões (micro e mesorregiões) do Paraná, com consulta on-line e download de documentos via Portal do IFPR; c) Organização de Revista de Desenvolvimento Regional para a produção científica de artigos, pesquisas, estudos de caso e projetos de extensão; d) Organização de Observatórios Locais em cada unidade do IFPR, instituindo grupos de trabalho em parceria com Observatório Regional.

Com relação ao Boletim Informativo, sugere-se que o material esteja organizado para o interesse de toda a Instituição; contudo, cada número priorizará informações de determinado Campus ou Unidade. A estrutura informacional do Boletim organiza-se em três partes: abrangência geográfica estadual, destacando-se informações gerais das unidades do IFPR; microrregional, na região de abrangência do Campus ou Campus Avançado; e detalhamento em nível local (Sede do Campus ou do Campus Avançado).

Além do Boletim Informativo, os demais materiais produzidos pelo Observatório seguem as seguintes etapas de trabalho: escolha do Campus para estudo; pesquisa e coleta de informações; organização em forma de tabelas, quadros e gráficos em planilha eletrônica; interpretação de dados em formato editor de texto; revisão textual; envio para assessoria de comunicação para tratamento visual e gráfico; revisão do material; convite à direção de Campus para apresentação do material e explicação; disponibilização em forma on-line na página do IFPR; e veiculação da notícia pelo setor de comunicação da instituição. O critério de prioridade na escolha do tema têm sido os Campi em fase de implantação. Posteriormente serão atendidos os demais Campi, considerando que estes já possuem estrutura e cursos em andamento. Alguns produtos tornam-se consequência dos existentes como: links para aprofundamento das informações, orientação e reflexão sobre o contexto das informações; disponibilização de eventos referentes ao Desenvolvimento Regional. Outros produtos, como a veiculação e visualização gráfica, dependem especialmente de tempo e pessoas de outros setores da instituição.

\section{Conclusão}

A fundamentação em documentos oficiais do histórico, do contexto e das razões para criação do Observatório Regional do IFPR sinalizou dois balizadores para a RFEPT do país. O primeiro refere-se à importância e relevância deste organismo

\footnotetext{
${ }^{38}$ Até o mês de março de 2014, já haviam sido disponibilizados dois volumes do Observatório Regional: Cenário Socioeconômico das Unidades do IFPR, sendo em versão impressa (ISSN 2318-8758) e on-line (ISSN 2318-874X).
} 
na expansão e manutenção dos IFETs como propulsores do desenvolvimento regional e local. O segundo é o desafio de se propor diretrizes comuns para a criação dos Observatórios na Rede, propiciando a formação de uma network de conhecimento técnico-científico e pedagógico dos Observatórios dentro e fora da rede pública. A realização de um fórum de discussão entre os promotores e principais usuários dos Observatórios pode ser o inicio de tal empreendimento. Além da melhoria em qualidade e quantidade de informações propiciadas pelo Observatório Regional, também há o desafio de construir ferramentas que auxiliem na seleção das melhores opções de cursos do Catálogo Nacional de Cursos Técnicos e sua adequação às demandas e viabilidades socioeconômicas regionais. Acredita-se que desta forma a iniciativa dos Observatórios estarão corroborando o desenvolvimento regional sustentável no país.

\section{Referências}

AZEVEDO, Maria I. L. A universidade e novos saberes. Quaestio: Revista de Estudos de Educação, Ano 3, n. 1, p. 65-83, mai., 2001.

BRASIL. Lei $\mathbf{N}^{\mathbf{0}}$ 9.394, de 20 de dezembro de 1996. Estabelece as diretrizes e bases da educação nacional. Presidência da República. Casa Civil. Subchefia para Assuntos Jurídicos. Disponível em: <http://www.planalto.gov.br/ccivil_03/leis/ 19394.htm>. Acesso em: 15 fev. 2014.

Decreto $\mathbf{N}^{\circ} \mathbf{5 . 7 7 3}$, de 9 de maio de 2006. Dispõe sobre o exercício das funções de regulação, supervisão e avaliação de instituições de educação superior e cursos superiores de graduação e sequenciais no sistema federal de ensino. Presidência da República. Casa Civil. Subchefia para Assuntos Jurídicos. Disponível em: <http://www.planalto.gov.br/ccivil_03/_ato2004-2006/ 2006/decreto/d5773.htm>. Acesso em: 5 fev. 2014.

Lei $\mathbf{N}^{\circ}$ 11.892, de 29 de dezembro de 2008. Institui a Rede Federal de Educação Profissional, Científica e Tecnológica, cria os Institutos Federais de Educação, Ciência e Tecnologia, e dá outras providências. Estabelece as diretrizes e bases da educação nacional. Presidência da República. Casa Civil. Subchefia para Assuntos Jurídicos. Disponível em: <http://www.planalto.gov.br/ccivil_03/ _ato2007-2010/2008/lei/111892.htm>. Acesso em: 16 fev. 2014.

. Relatório de Gestão 2010. Prestação de Contas Ordinária Anual. MEC02/2011/SETEC. Brasília: 02/2011. 
- Plano de Desenvolvimento da Educação: razões, princípios e programas (PDE). Ministério da Educação. Brasília. Disponível em: <http://portal.mec.gov.br/arquivos/livro>. Acesso em: 20 fev. 2014.

CABRAL, Augusto. A sociologia funcionalista nos estudos organizacionais: foco em Durkheim. Cadernos EBAPE [online].v. 2, n. 2, p. 1-15, 2004.

DELORS, Jacques. Educação: um tesouro a descobrir. Relatório para a UNESCO da Comissão Internacional sobre Educação para o século XXI. UNESCO/Cortez: São Paulo. 1998.

FERREIRA, Taísa; EUZEBIO, Gilson Luiz. Expansão para o interior: governo inicia processo de descentralização do ensino superior. Instituto de Pesquisa Econômica Aplicada (IPEA). Revista Desafios do Desenvolvimento. Ano 7, ed. 58, 26 fev., 2010.

FIEP. O que é um Observatório? Sistema Federação das Indústrias do Estado do Paraná/FIEP. Observatórios SESI/SENAI/IEL.

GASQUE, Kelley Cristine Gonçalves Dias; CUNHA, Marcus Vinícius. A epistemologia de John Dewey e o letramento informacional. TransInformação, Campinas, v. 22, n. 2, p. 139-146, maio/ago., 2010. Disponível em: $<$ http://revistas.puc-campinas.edu.br/transinfo/viewissue.php?id=25>. Acesso em: 31 ago. 2011.

GUIMARÃES, Alberto M. T. A interiorização da educação técnica no Brasil através da Rede E-Tec: o caso de sucesso do IFPR. V Seminário Internacional de Educação a Distancia (CAED). Anais... Minas Gerais, 2 a 4 de setembro de 2013.

HELLMANN, Gilmar J. Indicadores para avaliar a responsabilidade social nas instituições de ensino superior. Revista da FAE, Curitiba, v. 12, n. 2, jul./dez. 2009.

Relevância socioeconômica da geração de energia eólica no desenvolvimento regional sustentável: estudo de caso do Parque Eólico Água Doce. Dissertação de Mestrado. Departamento de Desenvolvimento Regional e Agronegócios da UNIOESTE, Toledo, 2013.

ILO. International Labour Organization. Agency of the United Nations. Genéve. 2014. Disponível em: <http://www.ilo.org/global/lang--en/index.htm>. Acesso em: 20 fev. 2014. 
INEP. Instituto Nacional de Estudos e Pesquisas Educacionais Anísio Teixeira. Legislação e Normas. Lei No 10.861, de 14 de abril de 2004. Conversão da MPv $n^{\circ}$ 147, de 2003. Institui o Sistema Nacional de Avaliação da Educação Superior SINAES e dá outras providências.

INSTITUTO FEDERAL - Rede Federal (IFRF). O PDI como ferramenta de gestão: orientações para a elaboração. Resultado das Reflexões do FDI - Fórum de Pró-Reitores de Desenvolvimento Institucional da RFEPT. Julho/2013.

INSTITUTO FEDERAL DO PARANÁ. Observatório Regional: cenário socioeconômico das unidades do IFPR. Campus Pitanga. Ano 1, n. 1, out./nov., Curitiba, 2013.

- Observatório Regional: cenário socioeconômico das unidades do IFPR.

Campus Capanema e Campus Avançado Barracão. Ano 2, v. 2, dez., 2013/jan., 2014.

. Plano de Desenvolvimento Institucional - PDI: 2009-2013.

. Relatório de auto-avaliação do IFPR de 2010. Comissão Própria de Avaliação. Curitiba, mar. 2011.

IOM. International Organization for Migration. Genéve. 2014. Disponível em: <https://www.iom.int/cms/home>. Acesso em: 25 fev. 2014.

MEC. PRONATEC. Programa Nacional de Acesso ao Ensino Técnico e Emprego. Dezembro de 2011.

MINISTÉRIO DA EDUCAÇÃO. Catálogo Nacional de Cursos Técnicos. Disponível em: <http://pronatec.mec.gov.br/cnct/eixos_tecnologicos.php>. Acesso em: 22 fev. 2014.

Sistema de acompanhamento de processos das Instituições de

Ensino Superior. Instruções para elaboração do plano de desenvolvimento institucional. Disponível em: <http://www2.mec.gov.br/sapiens/pdi.html>. Acesso em 05 jun. 2007.

MINISTÉRIO DA EDUCAÇÃO/INSTITUTOS FEDERAIS. Termo de Acordo de Metas e Compromissos: 2010-2022. 
MOREIRA, Daiane Magda Costa; RIBEIRO, Fabrício Américo Ribeiro. A Interiorização do Ensino Superior no Brasil: um estudo de caso do IFCE como promotor de desenvolvimento local na cidade de Canindé /CE. Anais... VII CONNEPI, 19 a 21 de outubro de 2012, Palmas/TO.

PNUD. Programa das Nações Unidas para o Desenvolvimento. Atlas do Desenvolvimento Humano no Brasil. 2013. Casa das Nações Unidas do Brasil. Brasília. Disponível em: <http://www.pnud.org.br>. Acesso em: 22 fev. 2014.

RAMOS, Mozart Neves Ramos. Andifes e os rumos das universidades federais. Associação Nacional dos Dirigentes das Instituições Federais de Ensino Superior (Andifes). Postado em 10 de janeiro de 2014.

SHEN, Li-Yin et al. The application of urban sustainability indicators: a comparison between various practices. Helsevier. Habitat International 35. 2011.

SILVA, Caetana Juracy Rezende et al. Institutos Federais Lei 11.892, de 29/12/2008: comentários e reflexões. Natal: IFRN, 2009.

SIQUEIRA, Carlos Eduardo; CARVALHO, Fernando. The observatory of the Americas as a network in environmental and worker health in the Americas. Ciências da saúde coletiva [online], v. 8, n. 4, p. 897-902, 2003.

Endereço para correspondência:

Gilmar Jose Hellmann - gilmar.hellmann@ifpr.edu.br Av. Victor Ferreira do Amaral, 306, Tarumã 82530-230 Curitiba/PR, Brasil 